\title{
McConnell patellar taping on postural control of women with patellofemoral pain syndrome: randomized clinical trial
}

\author{
Taping Patelar de McConnell no controle postural de mulheres com \\ síndrome da dor patelofemoral: Ensaio Clínico Randomizado
}

\author{
Daiene Cristina Ferreira ${ }^{[a]}{ }^{[a]}$ Rubens Alexandre da Silva Junior ${ }^{[a, b, c]}$, Cynthia Gobbi Alves Araújo ${ }^{[a, b]}$, \\ Paula Renata Mantovani ${ }^{\circledR}[\mathrm{a}]$, Christiane de Souza Guerino Macedo ${ }^{\circledR}[\mathrm{a}] *$
}

[a] Universidade Estadual de Londrina (UEL), Londrina, PR, Brasil

[b] Universidade Norte do Paraná (UNOPAR), Londrina, PR, Brazil

[c] University of Quebec at Chicoutimi (l'UQAC), Saguenay, Québec, Canada

\section{Abstract}

Introduction: The effects of McConnell patellar taping on the postural control of women with patellofemoral pain syndrome (PFPS) are controversial. Objective: To evaluate the effects of McConnell patellar taping on the static one-leg stance postural control and during squatting in women with PFPS. Method: A randomized, blinded clinical trial that comprised 40 women with PFPS, aged between 18 and 35 years. The study sample was allocated to two groups: McConnell patellar taping group (MPTG) and Placebo taping group (PTG). The analysis included the one-leg static support and squat on the lower limb with PFPS. The center of pressure (CoP) displacement parameters recorded by a force platform were analyzed using two-way ANOVA and Cohen's d. Results: For the static postural control, no significant differences were found between the groups in terms of time or interaction ( $p>0.05$ ); with small effect size. For the postural control during the one-leg squat, significant differences were found regarding the time of intervention for both groups, with reduced CoP parameters after the application of taping. However, the MPTG demonstrated a large effect size

*DCF: MS, e-mail: daiene_ferreira@hotmail.com RASJ: PhD, e-mail: rubens_dasilva@uqac.ca CGAA: MS, e-mail: cynthiagobbi@hotmail.com PRM: BS, e-mail: paular.mantovani@gmail.com CSGM: PhD, e-mail: chmacedouel@yahoo.com.br 
in frequency of oscillation and medium effect size in speed of oscillation, both during the squat exercise. Conclusion: McConnell patellar taping and placebo taping improved postural control during the one-leg squat. It should be observed that the changes and effect sizes determined for the MPTG were significantly higher compared to the PTG, emphasizing its clinical importance in the treatment of individuals with PFPS, during dynamic activities.

Keywords: Patellofemoral Pain Syndrome. Postural Balance. Knee. Physical Therapy.

\section{Resumo}

Introdução: Os efeitos do taping patelar de McConnell (TPM) para o controle postural de mulheres com síndrome da dor patelofemoral (SDPF) são controversos. Objetivo: Avaliar os efeitos do TPM no controle postural estático unipodal e agachamento unipodal em mulheres com SDPF. Método: O estudo é um ensaio clínico randomizado-cego, que avaliou 40 mulheres com SDPF, e idade entre 18 e 35 anos. A amostra foi randomizada em dois grupos: grupo taping patelar de McConnell (GTPM) e grupo placebo (GP). Avaliou-se o controle postural em apoio estático e agachamento unipodal, no membro inferior com SDPF. O deslocamento do centro de pressão (CoP) foi registrado por plataforma de força, e analisado com os testes ANOVA two way e tamanho do efeito (Cohen's d). Resultados: $O$ controle postural estático não apontou diferenças significativas entre os grupos, tempos ou interação $(P>0,05)$; com pequeno tamanho de efeito. $O$ controle postural em agachamento unipodal apresentou menor oscilação do centro de pressão para os dois grupos, com diferenças significativas em relação ao tempo de intervenção. No entanto, somente o GTPM demonstrou grande tamanho de efeito na frequência de oscilação e médio tamanho de efeito na velocidade de oscilação, durante o agachamento unipodal. Conclusão: O TPM e o placebo melhoraram o controle postural durante o agachamento unipodal. Deve-se observar que as mudanças e os tamanhos de efeito determinados para o GTPM foram significativamente maiores em relação ao GP, enfatizando sua importância clínica no tratamento de indivíduos com SDPF, durante atividades dinâmicas.

Palavras-chave: Síndrome da Dor Patelofemoral. Equilíbrio Postural. Joelho. Fisioterapia.

\section{Introduction}

Patellofemoral pain syndrome (PFPS) is multifactorial and associated with various functional disorders, such as dynamic knee valgus positioning, changes in muscle activity patterns of quadriceps and hip muscles, weakness in the quadriceps, and patellar misalignment [1-3]. Patellar misalignment has been associated with an increase in intra-articular contact, with cartilage overuse and degenerative alterations [4-6].

As a result of biomechanical changes, women with PFPS present alterations in static and dynamic postural control, which may affect their balance and body orientation while performing activities of daily living and physical and sports practice [7]. Citaker etal. [8] showed that the performance of women with PFPS was significantly worse on the unstable platform when compared to the control group. Silva et al. [9] defined that women with PFP have frontal dynamic postural stability deficit, while Chevidikunnan [10] established the importance of core muscles to improve the dynamic balance of women with PFPS. Thus, these studies highlight the importance of evaluating postural control in individuals with PFPS.

Although balance can be impaired by biomechanical distal factors, some studies have shown that individuals with PFPS also present changes in knee joint position sense, mostly due to the location of this dysfunction $[11,12]$. Thus, the McConnell method has been used to correct the patellar alignment as well as minimize knee pain, although a recent study [13] performed with pre and post magnetic resonance imaging of McConnell's taping with weight bearing on the lower limb showed that the taping technique did not change the area of contact of the patellofemoral joint or alignment of the patella after the medial correction. McConnell [14] proposed a technique using rigid self-adhesive taping on the patella to facilitate its alignment within the patellofemoral groove, and reduce intra-articular friction with consequent correction of biomechanical alterations through exercises without pain $[14,15]$.

Some studies have demonstrated that McConnell taping not only reduces pain [16,17], but also promotes 
greater dynamic balance, as determined by the Star Excursion Balance Test [18], better static unipodal balance [19], and greater vastus medialis activity relative to vastus lateralis in PFPS during a step-up and step-down and squat tests [20-22]. However, the literature does not present studies that analyzed the effect of McConnell taping on dynamic and functional movements such as squats. Still, the postural control associated with functional movements has not been analyzed in gold standard equipment as the force platform.

Thus, it is believed that the improvement of the postural control and balance of women with PFPS, through McConnell patellar taping, may facilitate the development of physical activities and daily life, and develop the necessary exercises to treat this dysfunction. In this way, faced with the contradictions presented by literature, the objective of the present study was to evaluate the effects of McConnell patellar taping and placebo taping on the static and dynamic postural control of women with PFPS, using a well-defined and controlled method.

\section{Methods}

The present study is the second part of a large research project entitled "The influence of femoro-patellar syndrome on neuromuscular responses and postural control". The first part evaluated the muscular activation in different proprioceptive exercises [2]. In a second moment, the participants were reevaluated when to the effect of McConnell patellar taping on postural control.

The present study is characterized a single blinded randomized clinical trial, with the two groups treated in parallel. The research was approved by the Research Ethics Committee of the institution (case N.1.268.020) and registered as a randomized, clinical trial on www. clinicaltrials.gov (NCT02841384).

\section{Sample}

The sample size and power were calculated using the Power and Sample Size Program, with 95\% confidence interval, power of $80 \%$, and significance level of $5 \%$, based on the data of a pilot study composed of McConnell patellar taping group (MPTG) and a placebo taping group (PTG). The sample size was estimated using the differences between the MPTG $(n=9)$ and the PTG $(n=9)$. A sample size of 20 patients per group was necessary due to a given anticipated dropout rate of $10 \%$.

Participants included in the McConnell patellar taping group (MPTG) and Placebo Taping Group (PTG) were sedentary women with previous retropatellar or knee pain during at least 3 of the following functional activities: squatting for long periods; going up / down stairs; kneeling; running or sitting for long periods; and who reported anterior knee pain of 3 or more on the Visual Analogue Scale (VAS) on the day of evaluation $[2,23,24]$.

The exclusion criteria, for both groups, included individuals with a history of severe knee injury, surgery on the locomotor system; luxation history; clinical evidence of meniscus injury; ligamentous instability; patellar tendinitis; presence of neurological, cardiovascular or rheumatologic diseases; pregnancy; diabetes; any change in plantar sensitivity; medication and/or physiotherapy treatment for PFPS, and hypersensitivity or allergy to tape.

Sixty-two women were invited to participate in the study; 21 did not attend the evaluation and 1 was excluded due to a musculoskeletal disorder. Therefore, the final sample was composed of 40 volunteers between the ages of 18 and 35 years, who were recruited from the physical therapy waiting list and the community. All participants were diagnosed with PFPS based on the clinical assessment of a qualified physiotherapist and were allocated randomly, by a professional outside the study, through the program www.ramdom.com, into two groups (MPTG and PTG), using opaque sealed envelopes.

\section{Equipment}

The participants were evaluated, by physical therapists, on a force platform - BIOMEC400 (EMG System Brazil). The system uses a 16-bit analog-to-digital converter and a $50 \mathrm{~Hz}$ notch. During data collection, the vertical ground reaction force signals were sampled at $100 \mathrm{~Hz}$. The digital data were transferred via USB cable. All force signals from the platform were filtered with a 35-Hz low-pass second-order Butterworth filter to cancel out noise. The bio-analysis software of the BIOMEC400 platform, which is compiled with computer routines of stabilographic analyses in MATLAB (The Mathworks, Natick, MA, USA), was used for acquisition and treatment of the balance parameters. 


\section{Procedures}

The participants responded to a questionnaire for characterization of the sample (age, weight, height, dominant lower limb, frequency of physical activity, limb with pain, pain history), the Patellofemoral Disorder Scale (Anterior Knee Pain Scale - AKPS), and the Visual Analogue Scale (VAS). The flowchart of the study is presented in Figure 1.

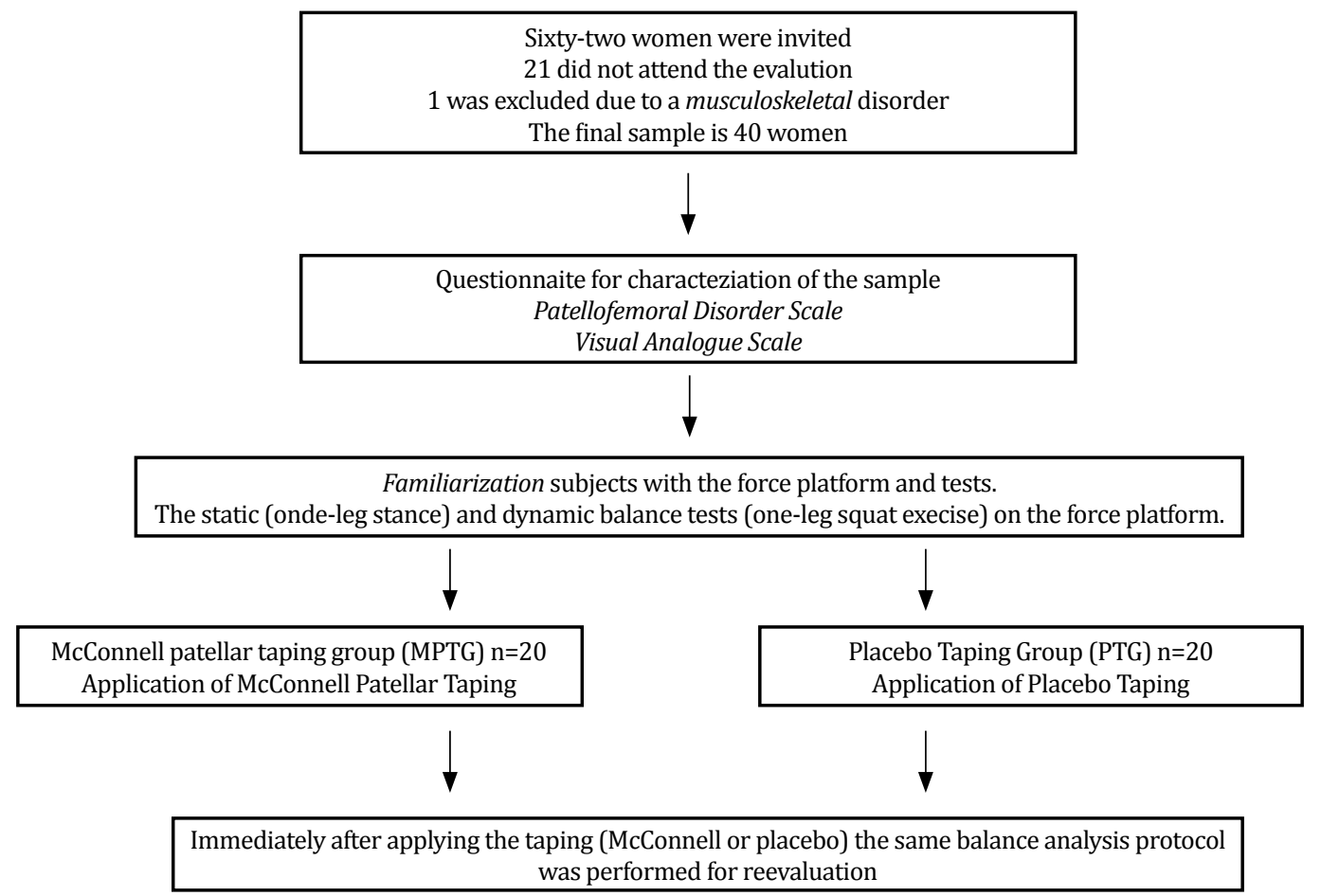

Figure 1- The flowchart of the study.

A training session was conducted prior to starting data collection to familiarize subjects with the force platform and tests to be carried out and prevent the learning effect. The static (one-leg stance) and dynamic balance tests (one-leg squat exercise) on the force platform were carried out in a sequence defined through a draw.

Static balance was evaluated with the participant remaining for 30 seconds in a one-leg position on the lower limb with pain, with the knee flexed and contralaterally suspended at approximately $90^{\circ}$. For the dynamic balance analysis, the participants performed three consecutive repetitions of the one-leg stance squat between approximately $0^{\circ}$ and $45^{\circ}$ of knee flexion in the lower limb with pain [25]. The contralateral leg was suspended and flexed at $90^{\circ}$. In both tests, the participants were instructed to stay balanced with the torso upright and remain as long as possible with the majority of the plantar region touching the ground. A target point to be looked at was fixed on the wall to help the volunteer maintain balance. The activity was performed three times, with a short rest in the sitting position between each repetition.

The interventions for each group were carried out as follows: For the MPTG (Figure 2-A), Johnson \& Johnson ${ }^{\circledR}$ rigid self-adhesive taping was positioned on the lateral border of the patella and tensioned up to the medial condyle of the femur, allowing stretching of the knee medial structures.

The taping technique used was that proposed by McConnell [14] to realign the patella position [14,25]. For placebo taping (Figure 2-B) the same Johnson \& Johnson ${ }^{\circledR}$ rigid taping was applied vertically on the knee flexed at $90^{\circ}$, without any stretching of the lateral structures of the knee. 


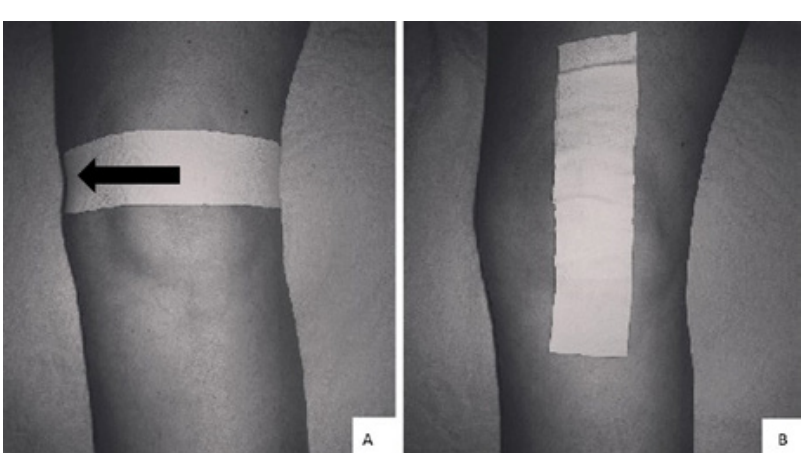

Figure 2 - $A=$ McConnell patellar taping. $B=$ Placebo taping.

Immediately after applying the taping (McConnell or placebo) the same balance analysis protocol was performed for reevaluation.

\section{Statistical Analysis}

The following balance parameters were considered for data analysis: the area of the center of pressure oscillation (A-CoP), displacement, and mean speed and mean frequency in both anteroposterior (AP) and mediolateral (ML) directions.

Data were tabulated and submitted to statistical analysis using SPSS version 20 for Windows (SPSS Inc., Chicago, IL, USA). The normality of data distribution was confirmed by the Shapiro-Wilk testand expressed as mean and standard deviation. Two-way ANOVA was applied to compare the effects on both groups (taping and placebo) of time (pre and post-intervention) and interaction. A confidence interval of $95 \%$ was established and $P$ values $<0.05$ were considered to indicate statistical significance.

To verify the effect size $(d)$, the following formula was used: $d=\left(x_{1}-x_{2}\right)$ /averages of the standard deviations (SDs), where $x 1$ is the average of the analyzed variable in the initial assessment, and $x_{2}$ is the average of the analyzed variable in the final assessment. The average of the SDs was calculated through the arithmetic mean of the standard deviations related to the initial and final assessment: $\left(\mathrm{SD}_{1}+\mathrm{SD}_{2}\right) / 2$.

The effect size was defined as $\leq 0.5$ representing a small effect, between $>0.5$ and $\leq 0.8$, a medium effect, and $>0.8$, a large effect [26].

\section{Results}

The groups (MPTG and PTG) were homogeneous regarding the demographic data and clinical status (Table 1).

Table $\mathbf{1}$ - Characteristics of the participants

\begin{tabular}{lcc}
\hline & $\begin{array}{c}\text { MPTG } \\
(\mathbf{n}=\mathbf{2 0})\end{array}$ & $\begin{array}{c}\text { PTG } \\
(\mathbf{n}=\mathbf{2 0})\end{array}$ \\
Age (years) & $23.75(3.35)$ & $23.55(3.41)$ \\
Weight (Kg) & $60.19(10.39)$ & $61.99(14.39)$ \\
Height (meters) & $1.58(0.05)$ & $1.62(0.06)$ \\
BMI & $23.86(3.62)$ & $23.45(4.73)$ \\
VAS & $5.95(1.79)$ & $6.3(1.78)$ \\
AKPS & $73.75(11.11)$ & $72.35(11.06)$ \\
\hline
\end{tabular}

Note: (...) Demographic data are expressed as mean and standard deviation established by the Student t-test. No significant differences were found between groups for any variables $(P>0.05)$. MPTG - McConnell patellar taping group. PTG - Placebo taping group.

The comparison of the results obtained from the static postural control evaluation did not demonstrate significant differences between groups or intervention times evaluated. There were no significant interactions between groups or intervention times (Table 2).

Table 2 - Center of pressure variables for static postural control

\begin{tabular}{|c|c|c|c|c|c|c|}
\hline \multirow[t]{2}{*}{ Variable } & & \multicolumn{2}{|c|}{ Groups } & \multicolumn{3}{|c|}{ P Anova } \\
\hline & & MPTG & PTG & Group & Time & Interaction \\
\hline Area of $\mathrm{CoP}\left(\mathrm{cm}^{2}\right)$ & $\begin{array}{l}\text { PRE } \\
\text { POST }\end{array}$ & $\begin{array}{l}6.83(3.10) \\
6.81(3.00)\end{array}$ & $\begin{array}{l}6.99(2.17) \\
6.90(2.20)\end{array}$ & 0.829 & 0.922 & 0.959 \\
\hline AP Amplitude (cm) & $\begin{array}{l}\text { PRE } \\
\text { POST }\end{array}$ & $\begin{array}{l}3.77(1.25) \\
3.63(0.90)\end{array}$ & $\begin{array}{l}3.57(0.66) \\
3.62(0.72)\end{array}$ & 0.623 & 0.840 & 0.622 \\
\hline ML Amplitude (cm) & $\begin{array}{l}\text { PRE } \\
\text { POST }\end{array}$ & $\begin{array}{l}2.79(0.48) \\
2.65(0.44)\end{array}$ & $\begin{array}{l}2.86(0.37) \\
2.77(0.38)\end{array}$ & 0.311 & 0.230 & 0.853 \\
\hline AP Speed $(\mathrm{cm} / \mathrm{s})$ & $\begin{array}{l}\text { PRE } \\
\text { POST }\end{array}$ & $\begin{array}{l}2.16(0.60) \\
2.00(0.48)\end{array}$ & $\begin{array}{l}2.09(0.44) \\
1.97(0.47)\end{array}$ & 0.647 & 0.216 & 0.854 \\
\hline
\end{tabular}




\begin{tabular}{lcccccc}
\hline Variable & \multicolumn{2}{c}{ Groups } & \multicolumn{3}{c}{ P Anova } \\
& & MPTG & PTG & Group & Time & Interaction \\
ML Speed (cm/s) & PRE & $2.50(0.56)$ & $2.43(0.44)$ & 0.718 & 0.064 & 0.803 \\
& POST & $2.27(0.46)$ & $2.26(0.44)$ & & & \\
AP Frequency (Hz) & PRE & $0.54(0.09)$ & $0.54(0.15)$ & 0.932 & 0.401 & 0.891 \\
& POST & $0.52(0.14)$ & $0.52(0.13)$ & & & \\
ML Frequency (Hz) & PRE & $0.78(0.13)$ & $0.73(0.13)$ & 0.099 & 0.200 & 0.993 \\
\hline
\end{tabular}

Note: (...) Values are expressed as mean and standard deviation established by two-way ANOVA. MPTG - McConnell patellar taping group. PTG - Placebo taping group. CoP - center of pressure oscillation. AP - anteroposterior. ML - mediolateral. cm - centimeters. $\mathrm{Hz}$ - Hertz.

The evaluation of dynamic postural control revealed significant differences in time for both the placebo and McConnell patellar taping groups in ML speed and AP and ML frequency. Greater changes were observed between the initial and final values in the McConnell patellar taping group (Table 3).

Table 3 - Center of pressure variables for dynamic postural control, pre and post intervention

\begin{tabular}{|c|c|c|c|c|c|c|}
\hline \multirow[t]{2}{*}{ Variable } & & \multicolumn{2}{|c|}{ Groups } & \multicolumn{3}{|c|}{ P Anova } \\
\hline & & MPTG & PG & Group & Time & Interaction \\
\hline Area of $\mathrm{CoP}\left(\mathrm{cm}^{2}\right)$ & $\begin{array}{l}\text { PRE } \\
\text { POST }\end{array}$ & $\begin{array}{l}13.34(7.16) \\
13.69(7.09)\end{array}$ & $\begin{array}{l}14.35(6.13) \\
14.06(5.10)\end{array}$ & 0.633 & 0.980 & 0.823 \\
\hline AP Amplitude (cm) & $\begin{array}{l}\text { PRE } \\
\text { POST }\end{array}$ & $\begin{array}{l}5.69(1.93) \\
5.79(2.10)\end{array}$ & $\begin{array}{l}6.04(1.80) \\
6.09(1.62)\end{array}$ & 0.437 & 0.864 & 0.963 \\
\hline ML Amplitude (cm) & $\begin{array}{l}\text { PRE } \\
\text { POST }\end{array}$ & $\begin{array}{l}3.36(0.64) \\
3.25(0.50)\end{array}$ & $\begin{array}{l}3.39(0.38) \\
3.25(0.47)\end{array}$ & 0.892 & 0.257 & 0.871 \\
\hline AP Speed $(\mathrm{cm} / \mathrm{s})$ & $\begin{array}{l}\text { PRE } \\
\text { POST }\end{array}$ & $\begin{array}{l}3.61(0.88) \\
3.33(0.74)\end{array}$ & $\begin{array}{l}3.59(0.70) \\
3.38(0.66)\end{array}$ & 0.929 & 0.154 & 0.857 \\
\hline ML Speed $(\mathrm{cm} / \mathrm{s})$ & $\begin{array}{l}\text { PRE } \\
\text { POST }\end{array}$ & $\begin{array}{c}3.37(0.66) \\
2.95(0.49)^{\star *}\end{array}$ & $\begin{array}{c}3.29(0.58) \\
3.09(0.67)^{\star *}\end{array}$ & 0.845 & $0.026^{\star}$ & 0.420 \\
\hline AP Frequency (Hz) & $\begin{array}{l}\text { PRE } \\
\text { POST }\end{array}$ & $\begin{array}{c}0.67(0.17) \\
0.57(0.15)^{\star \star}\end{array}$ & $\begin{array}{c}0.61(0.21) \\
0.53(0.15)^{\star \star}\end{array}$ & 0.246 & $0.028^{*}$ & 0.714 \\
\hline ML Frequency (Hz) & $\begin{array}{l}\text { PRE } \\
\text { POST }\end{array}$ & $\begin{array}{c}0.90(0.14) \\
0.80(0.11)^{\star *}\end{array}$ & $\begin{array}{l}0.83(0.15) \\
0.81(0.13)\end{array}$ & 0.326 & $0.035^{\star}$ & 0.219 \\
\hline
\end{tabular}

Note: (...) Mean values with standard deviations. MPTG - McConnell patellar taping group. PTG - Placebo taping group. CoP - center of pressure oscillation. AP - anteroposterior. ML - mediolateral. $\mathrm{cm}$ - centimeters. $\mathrm{Hz}$ - Hertz. *Differences established by two-way ANOVA. **Difference established by Student $\mathrm{t}$-test for comparison of intervention times between groups.

Significant effect sizes were observed for dynamic postural control in the MPTG: mean ML frequency (difference of $0.10 \mathrm{~Hz}$ and a large effect size - $\mathrm{d}=0.83$ ), ML speed (difference of $0.42 \mathrm{~Hz}$ and a medium effect size $\mathrm{d}=0.73$ ), and mean AP frequency (difference of $0.10 \mathrm{~Hz}$ and a medium effect size $-\mathrm{d}=0.62$ ). The remaining variables analyzed for static and dynamic postural control presented a small effect size $(\mathrm{d} \leq 0.5)$ in both groups.

\section{Discussion}

Maintenance of balance and body orientation is essential to perform normal activities of daily life, and to practice physical activity and sports [7]. Therefore, the methods used to evaluate, detect, and improve balance disorders play an importance role in prevention and rehabilitation. 
Our results obtained from the comparison between the pre- and post-intervention applications demonstrated significant improvement in dynamic postural control in the McConnell patellar taping group (MPTG) and Placebo taping group (PTG). The results observed in the MPTG are consistent with those reported by Felício [19] and point out the possibility of changes in postural adjustment reactions arising from additional sensory input (proprioceptive feedback) and patellar alignment correction. The improvement in postural control in dynamic activities corroborate the data described by Powers [27] and Crossley [28], which showed improved knee flexion after applying McConnell taping during non-weight-bearing exercises and possible assistance in reducing body sway. In contrast, the improvement in postural control in the PTG was unexpected since no forces were applied to the medialization of the patella. However, this could be justified by the results described by Sawkins [29], who evaluated the placebo effect on ankle instability and showed that individuals submitted to this method demonstrated increased perceptions of stability, confidence, and reassurance compared to the control group (without taping).

In addition, Tamburella et al. [30] explained that the effects of applying pressure to and stretching the skin can stimulate cutaneous mechanoreceptors and enhance signal information of joint movement or joint position. Petersen, et al. [31] discusses on results from studies in which placebo taping applications reduced pain in patellofemoral pain syndrome patients, and suggest that the benefits of these applications also occur through sensory effects on the skin. Barton et al. [32] also demonstrated that patellar taping may have an effect on spinal level excitation via afferent mediation of anterior horn cells supplying the quadriceps, through the mechanical effect on the muscle spindles and Golgi tendon organs or by skin afferents, which may have contributed to the improvement observed in the PTG.

The results of this study did not demonstrate any significant differences between the groups in the comparisons of static and dynamic postural control after using McConnell patellar taping and placebo taping. These data did not confirm the initial hypothesis of the study, since more significant results were expected, with better values for the MPTG. A possible explanation for this non-differentiation was the good performance status of the groups to perform activities of daily living, with a score between 64.5 and 80 on the Anterior Knee Pain Scale [33,34]. Although both groups had PFPS, the participants exhibited a maximum score $(73.75$ points in the MPTG and 72.35 in the PG), and consequently, a low level of functional limitation. These findings may explain why the groups did not present any significant differences for the postural control variables analyzed.

On the other hand, medium to large effect sizes were observed in the analysis of dynamic postural control in the MPTG, while the effect size of placebo taping was small for all variables. This was an important result considering that the intervention provided improvement to patients and can contribute to the clinical practice of physiotherapists. Furthermore, that the benefits pointed out by the large effect size may be associated with the results of Lee and Cho [35] that examined the effect of McConnell taping applied to patients with PFPS on the changes in muscle activity of the vastus medialis and vastus lateralis during squatting and found that it affected the activity of the quadriceps by changing the position of the patellar, and thus could be an effective treatment for PFPS, and Leibbrandt and Louw [36] who observed that the patellofemoral joint reaction force was significantly reduced during the one-leg squat after applying McConnell patellar taping to the symptomatic knee and made the movement easier.

This study contained limitations which include the sample size, the low age of the sample (18-35 years) and the high scores obtained in the AKPS. Although both groups had PFPS, they were very close to the cutoff point established by the literature, which could characterize normal or near normal function. Also, the initial project registered in the clinical trials had two more tests (up and down stairs and sitting and lifting) that could not be added to the tests of the present study, because in the pilot project we observed that using all four functional tests together increased participant's knee pain. Possibly the AKPS could be used in further studies and discussions as an inclusion criterion, with a lower score limit for inclusion in the PFPS group. Also, future studies could include a group without any intervention to establish the tactile effect of the bandage on postural control and the evaluator could be blind if the participant wore pants to hide the bandage used.

\section{Conclusion}

The results indicated that both McConnell patellar taping and placebo taping were successful in improving the dynamic postural control of the women with PFPS evaluated in this study, which emphasizes the sensory stimulation that the two approaches can provide. It should be observed that the effect sizes produced by 
McConnell patellar taping were large (mediolateral frequency) and medium (mediolateral speed and anteroposterior frequency) when compared to the PTG.

\section{Acknowledgments}

This search did not receive any specific grant awards from public, commercial, or non-profit funding agencies.

\section{References}

1. Logan CA, Bhashyam AR, Tisosky AJ, Haber DB, Jorgensen A, Roy A PM. Systematic Review of the Effect of Taping Techniques on Patellofemoral Pain Syndrome. Sports Health. 2017;9(5):456-61.

2. Araújo CGA, Macedo CSG, Ferreira D, Shigaki L SR. Mcconnell's patelar taping does not alter knee and hip muscle activation differences during proprioceptive exercises: A randomized placebo-controlled trial in women with patellofemoral pain syndrome. J Electromyogr Kinesiol. 2016;31:72-80.

3. Sanchis-Alfonso V, McConnell J, Monllau JC FJ. Diagnosis and treatment of anterior knee pain. JSAKOS. 2016;1:161-73.

4. Schwane BG, Goerger BM, Goto S, Blackburn JT, Aguilar AJ P DA. Trunk and Lower Extremity Kinematics During Stair Descent in Women With or Without Patellofemoral Pain. J Athl Train. 2015;50(7):704-12.

5. Powers CM, Landel R PJ. Timing and intensity of vastus muscle activity during functional activities in subjects with and without patellofemoral pain. Phys Ther. 1996;76(9):946-55.

6. Karst GM, Willett WG. Onset timing of electromyographic activity in the vastus medialis oblique and vastus lateralis muscles in subjects with and without patellofemoral pain syndrome. Phys Ther. 1995;75(9):813-23.

7. Duarte M, Freitas SMFS. Revisão sobre posturografia baseada em plataforma de força para avaliação do equilíbrio. Rev Bras Fisioter. 2010;14(3):183-92.

8. Citaker S, Kaya D, Yuksel I, Yosmaoglu B, Nyland J, Atay O A DMN. Static balance in patients with patellofemoral pain syndrome. Sports Health. 2011;3(6):524-7.
9. Silva APMCC, Almeida GPL, Magalhães MO, França FJR, Ramos LAV, Comachio J MA. Dynamic postural stability and muscle strength in patellofemoral pain: Is there a correlation? Knee. 2016;23(4):616-21.

10. Chevidikunnan MF, Al Saif A, Gaowgzeh RA MK. Effectiveness of core muscle strengthening for improving pain and dynamic balance among female patients with patellofemoral pain syndrome. J Phys Ther Sci. 2016;28(5):1518-23.

11. Callaghan MJ, Selfe J, Bagley PJ, Oldham JA. The effects of patellar taping on knee joint proprioception. J Athl Train. 2002;37(1):19-24.

12. Callaghan MJ, Selfe J, Mchenry A, Oldham JA . Effects of Patellar taping on knee joint proprioception in patients with patellofemoral pain syndrome. Man Ther. 2008;13(3):192-9.

13. Ho KY, Epstein R, Garcia R, Riley N, Lee SP. Effects of Patellofemoral Taping on Patellofemoral Joint Alignment and Contact Area During Weight Bearing. J Orthop Sport Phys Ther. 2017;47(2):115-32.

14. McConnell J. The management of chondromalacia patellae: a long term solution. Aust J Physiother. 1986;215-23.

15. Pfeiffer RP, DeBeliso M, Shea KG, Kelley L, Irmischer B, Harris C. Kinematic MRI assessment of McConnell taping before and after exercise. Am J Sport Med. 2004;32( 3):621-28.

16. Whittingham M, Palmer S, Macmillan F. Effects of taping on pain and function in patellofemoral pain syndrome: a randomized controlled trial. J Orthop Sport Phys Ther. 2004;34(9):504-10.

17. Salsich GB, Brechter JH, Farwell D, Christopher MP. The effects of patelar taping on knee kinetics, kinematics, and vastus lateralis muscle activity during stair ambulation in individuals with patellofemoral pain. J Orthop Sport Phys Ther. 2002;32(1):3-10.

18. Aminaka N GP. Patellar Taping, Patellofemoral Pain Syndrome, Lower Extremity Kinematics, and Dynamic Postural Control. J Athl Train. 2008;43(1):21-8.

19. Felicio LR, Masull CL, Saad MC Bevilaqua-Grossi D. The Effect of a Patellar Bandage on the Postural Control of Individuals with Patellofemoral Pain Syndrome. J Phys Ther Sci. 2014;26(3):461-4. 
20. Christou EA. Patellar taping increases vastus medialis oblique activity in the presence of patellofemoral pain. J Electromyogr Kinesiol. 2004;14(4):495-504.

21. Ng G, Cheng J. The effects of patellar taping on pain and neuromuscular performance in subjects with patellofemoral pain syndrome. Clin Rehabil. 2002;16(8):821-7.

22. Cowan SM, Bennell KL, Hodges PM. Therapeutic patellar taping changes the timing of vasti muscle activation in people with patellofemoral pain syndrome. Clin J Sport Med. 2002;12(6):339-47.

23. Santos G, Say K, Pulzato F, Oliveira AS, Bevilaqua-Grossi D, Monteiro-Pedro V. Relação eletromiográfica integrada dos músculos vasto medial oblíquo e vasto lateral longo na marcha em sujeitos com e sem síndrome de dor femoropatelar. Rev Bras Med Esporte. 2007;13(1):17-21.

24. Mostamand J, Bader DL, Hudson Z. The effect of patellar taping on joint reaction forces during squatting in subjects with patellofemoral pain syndrome. J Bodyw Mov Ther. 2010;14(4):375-81.

25. Mostamand J, Bader DL HZ. Reliability testing of vasti activity measureme in taped and untaped patellofemoral conditions during single leg squatting in healthy subjects: A pilot study. Journal o. J Bodyw Mov Ther. 2013;17(3):271-7.

26. Cohen J. Statistical power analysis for the behavioral sciences. New York: LEA; 1990. 567 p.

27. Powers CM, Landel R, Sosnick T, Kirby J, Mengel K, Cheney A, Perry J. The effects of patellar taping on stride characteristics and joint motion in subjects with patellofemoral pain. J Orthop Sport Phys Ther. 1997;26(6):286-91.

28. Crossley K, Cowan SM, Bennell KL, Mcconnell J. Patellar taping: is clinical success supported by scientific evidence? Man Ther. 2000;5(3):142-50.
29. Sawkins K, Refshauge K, Kilbreath S, Raymond J. The Placebo effect of ankle taping in ankle instability. Med Sci Sport Exerc. 2007;39(5):781-7.

30. Tamburella F, Scivoletto G, Molinari M. Somatosensory inputs by application of KinesioTaping: effects on spasticity, balance, and gait in chronic spinal cord injury. Front Hum Neurosci. 2014;30(8):367.

31. Petersen W, Rembitzki I, Liebau C. Patellofemoral pain in athletes. J Sports Med. 2017;143-54.

32. Barton C, Balachandar V, Lack S, Morrissey D. Patellar taping for patellofemoral pain: a systematic review and metaanalysis to evaluate clinical outcomes and biomechanical mechanisms. Br J Sport Med. 2014;48(6):417-24.

33. Fukuda TY, Magalhaes E, Sacramento SR, Forgas A, Cohen M, Abdalla RJ. A comparision of hip strenght between sedentary females with ou without patellofemoral pain syndrome. J Orthop Sport Phys Ther. 2010;40(10):641-7.

34. Bolgla LA, Malone TR, Umberger BR, Uhl TL. Hip strength and hip and knee kinematics during stair descent in females with and without patellofemoral pain syndrome. J Orthop Sport Phys Ther. 2008;38(1):12-8.

35. Lee SE, Cho SH. The effect of McConnell taping on vastus medialis and lateralis activity during squatting in adults with patellofemoral pain syndrome. J Exerc Rehabil. 2013;9(2):326-30.

36. Leibbrandt DC, Louw QA. The use of McConnell taping to correct abnormal biomechanics and muscle activation patterns in subjects with anterior knee pain: a systematic review. J Phys Ther Sci. 2015;27(7):2395-404.

Submetido: $23 / 12 / 2017$

Aprovado: 03/02/2020

Approved in: 02/03/2020

Aprovado: 03/02/2020 